\title{
Cuban Medical Education: Aiming for the Six-Star Doctor
}

\section{By lleana del Rosario Morales Suárez, MD, MS, José A. Fernández Sacasas, MD, MS and Francisco Durán García, MD}

Profound changes are under way in Cuban medical education. Some aspects of this transformation represent radical shifts, others a deepening of processes already in motion. Together, these changes reflect a progressive sense of urgency over the last four decades to: 1) scale up physician training to meet the needs of the whole population; 2) recruit and train scientifically prepared and socially committed students; and 3) match competencies, knowledge base, and scope of responsibilities to the concrete health needs of people in Cuba and other countries where these future physicians may serve.

These three goals have guided successive innovations in Cuban medical education since the early 1960s, when the University of Havana Medical School was left with only 23 of its 161 professors - the rest either emigrating or in disagreement with academic and health care reforms designed to guarantee the right to health care. From a fee-for-service model catering mainly to individual patients, health care was being transformed into a universal public health system. This required decentralization of medical services - first to the rural areas of the country, which had essentially gone without - followed by development of a nationwide primary health care network. Thus, from the beginning, there was an urgent need to train many more physicians and to train physicians prepared for, and committed to, this new vision.

An initial commitment appeared early: in 1959, students in their last year of medical training held a series of stormy meetings that resulted in a majority decision to volunteer to go where they were

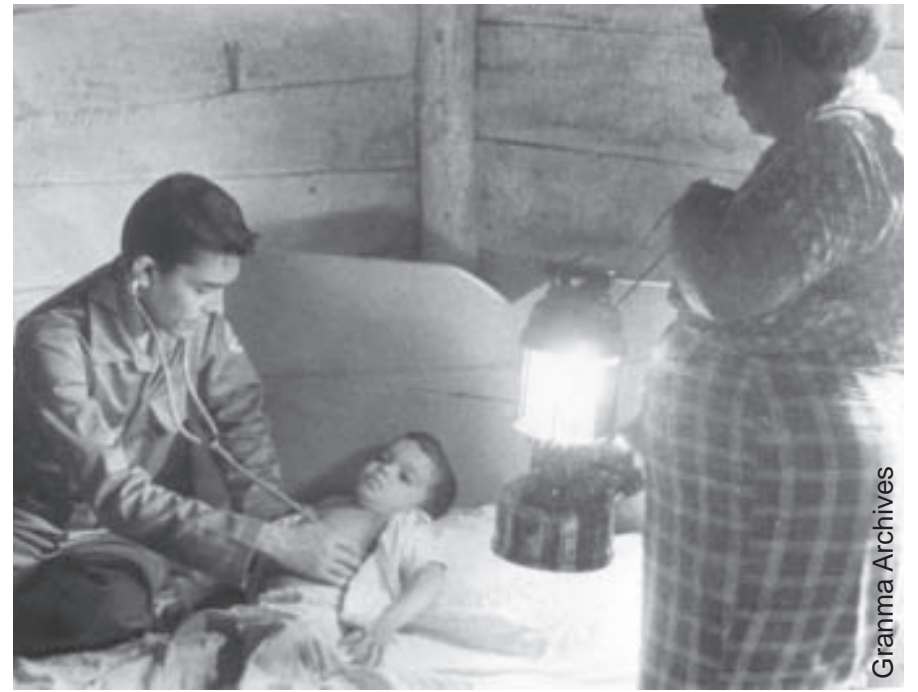

Doctor in the Rural Medical Service, cerca 1960.

most needed - the Cuban countryside. They presented their initiative to the Ministry of Public Health, which promptly created an initial 318 new jobs for them in the mountains. This was the genesis of the Rural Medical Service that would involve hundreds of recent graduates over the next decade and lay the foundation for laws that would establish community service as a requirement. Since the 1960s, Cuban medical graduates also pledge their commitment to practice in the public health system, providing their services free to all who require them.[1]

\footnotetext{
Highlights in the History of Cuban Medical Education

1726

1728

1842

1919

1942

1956

1959

1963

1970 s

1976

1980s

1982

$1982-1985$

1984

1984

1986

1996

1997

1999

2000

2004-2005

2007-2008

Medicine first taught in Cuba by the Dominican Order.

The University of Havana founded, including Faculty of Medicine.

University of Havana becomes secular; medical curriculum reformed with more scientific emphasis; clinical medicine introduced.

Six-year Flexnerian program adopted, devoted to basic, preclinical and clinical sciences.

Flexnerian model improved for individual patient care; includes hospital-based teaching with students, interns and residents.

University of Havana closed under General Batista.

University's Faculty of Medicine re-opens with 23 of its former staff of 161 professors.

Emergency curriculum introduced to increase enrollment in order to staff public health system.

Creation of comprehensive-care community polyclinic as main primary care model.

Medical education turned over to Ministry of Public Health. Creation of Higher Institutes of Medical Sciences in Havana, Santa Clara and Santiago de Cuba.

Medical specialties expanded to 54; medical schools established throughout Cuban provinces.

Medical student selection criteria strengthened to include vocation and motivation as well as academic performance.

Curriculum reform to produce Basic General Physician (BGP) for family doctor program. More training in community

settings, but medical school campus- and hospital-based emphasis maintained.

Introduction of family doctor program.

Comprehensive General Medicine (Family Medicine) created as new specialty.

First national state licensing exams applied; practical and theoretical. External examiners used.

Quality Assurance Pillars for Medical Education: stronger requisites for accreditation of teaching centers established.

Continuing medical education credit system implemented.

Master's program in medical education introduced.

Latin American Medical School established.

Virtual University of Health founded for distance learning.

University Polyclinic program piloted in 75 polyclinics; practicing primary care specialists become physician-tutors.

Morphophysiology introduced for all medical students in first two years, integrating basic science subjects into one discipline.
}

Sources: Delgado García G. Desarrollo histórico de la enseñanza médica superior en Cuba desde sus orígenes hasta nuestros días. Educ Med Super 2004;18(1):14-26; and data furnished by Ministry of Public Health, Vice Ministry for Medical Education and Research. 
Reference to the Rural Medical Service is helpful in understanding the evolution of Cuban medical education, since it offers early insight into essential features of the health system and the kind of doctor required to fulfill its mandate. In memoirs and interviews, physicians from that first generation place great importance on their time in the mountains as recent graduates, often providing the first medical services ever to reach families steeped in years of poverty. The experience sensitized them to the plight of Cuba's rural population, and practicing in isolated areas also sharpened their skills and decision-making abilities. One report on the period notes: "The doctors lived in people's huts, where they also saw patients...At first, their role was purely to care for the sick, given the huge numbers of people who came to see them daily. With time, as the doctor-patient relationship developed and as the doctors became more integrated into the communities, their social and educational role came into its own." By the third wave of rural doctors, the report concludes, "The doctor has become an important figure in these rural communities, establishing a relationship never seen before with local people."[2]

\section{Changes in Medical Education}

As health system reforms moved forward, medical education was not fully attuned to the values, competencies and staffing needs that were beginning to crystallize as the foundation for extending primary care and comprehensive health services to the entire $\mathrm{Cu}$ ban population.

A decisive step toward better aligning education with health and workforce needs was taken in 1976 when training of human resources for health was transferred from the Ministry of Education (MINED) and Ministry of Higher Education (MES) to the Ministry of Public Health (MINSAP). Since then, while academic requisites for degrees in the health field continue to be established and monitored by the two education ministries, it is MINSAP that defines the knowledge base, competencies and scope of responsibility; designs curriculum; confers the degrees; and provides education for each of the current five university-level health sciences professions. These are: medicine, dentistry, nursing, clinical psychology, and various fields of health technology.

Over time, MINSAP's role has made the Cuban population's health profile and the health system's staffing needs determining factors in medical school curriculum development - often providing impetus for curriculum reform.

Two related initiatives constitute another critical step for Cuban medical education: extension of medical training centers throughout the country by the 1980s, enabling students to train in their home provinces where they would eventually practice; and expansion of post-graduate training to the current 54 specialties, enabling more robust secondary and tertiary facilities to accommodate patient referrals and enhancing the health system's research capabilities. Today, the country has 25 medical schools.

A third important step, taken in 1982, was the establishment of a more selective admission process by increasing academic requirements and including new non-academic elements that called for medical school faculty to visit high schools, interview prospective students and consult their classmates regarding applicants' motivations, vocation, and sense of solidarity and responsibility.

\section{A New Kind of Family Doctor}

The most far-reaching curricular reform to date was initiated in the early 1980s, a direct result of the newly launched family doctorand-nurse program that would revolutionize health care in Cuba. In line with the principles of the 1978 Alma-Ata Declaration emphasizing the fundamental role of primary health care in achieving universally accessible services, the program was piloted in Havana's Lawton district in 1983 and extended nationally beginning in 1984 . By 1999, the doctor-and-nurse health care teams were working in $98 \%$ of Cuban neighborhoods.

Each team was responsible for the health of 120-150 families in their geographic area. In practice, this meant morning visits by patients to the office and afternoon house calls for the team, interspersed with health promotion activities. Family doctors in a given community were clustered around a local polyclinic (serving 20,000 to 40,000 inhabitants), relying on it for referrals to specialists, laboratory and other diagnostic services, and organizational support. Family doctors were also posted in large factories and schools, on board ships, in senior homes, and other settings. The new curricular model was designed to graduate a Basic General Doctor after six years, who would staff a family doctor office while pursuing a residency in comprehensive general medicine (family medicine). By the 1990s, this residency was required of virtually all Cuban medical graduates before opting for a second specialty, should they choose to do so.

Formulation of the new basic medical education curriculum was guided by Dr Fidel Ilizástigui Dupuy, then Vice Rector for Development at the Higher Institute of Medical Sciences of Havana, who presided over a national commission that included medical educators, practitioners, Ministry of Higher Education representatives, and students. The Commission drew up the new curriculum through a three-year process of consultations and workshops involving all the medical schools in the country, and their final proposal was presented to MINSAP and MES for discussion and approval. In the process, the commission analyzed government guidelines; MES methodological documents; opinions from an array of faculty and practitioners; Cuban health indicators on morbidity, mortality and general health; characterization of the role of the Cuban family physician; and medical education experiences in Cuba and several other countries. For example, teams visited medical schools in Canada, the United States, the USSR, France, and the UK and other nations.

The commission identified 286 health problems that graduates should be able to address at the primary care level, constituting the first innovation in the program: concrete population health needs were the starting point, not the end point, for training. They also defined the professional profile of the doctor they aimed to train, specifying that these primary care physicians should be able to:

- Provide comprehensive medical care to individuals and their families in the context of their social surroundings, through health promotion, disease prevention, diagnosis, treatment and rehabilitation, carried out through a bio-psycho-social-environmental approach based on a primary health care model;

- Carry out research, teaching, and individual study;

- Manage health care programs, facilities, and resources;

- Effectively communicate with patients, their families, and the community to generate participation in building health;

- Apply the scientific method, critically assimilating scientific information; and 
- Project humanistic ethical values, including a vocation for service, human solidarity, and commitment to preserving the lives and health of Cubans and others who require their services.

As a result, several theoretical and practical innovations were incorporated into the new curricular model, including:

- Conceptualization of medicine as a sociobiological science, and of the curriculum as a whole, its contents interwoven to facilitate understanding of real-life processes.

- Introduction of problem-based and other active learning methods, increasing students' cognitive independence and reducing memorization.

- Increased proportion of epidemiological and public health sciences in the curriculum.

- Introduction of medical skills and basic clinical sciences at an earlier stage in training, with biomedical sciences closely linked to the practice of medicine.

- Improved teaching methods, with emphasis on service learning.

- Creation of Comprehensive General Medicine (Family Medicine) Departments in all medical schools.

- Requiring a passing grade on the practical portion of an exam as a prerequisite to taking the theoretical portion: an approach that emphasizes specific skills to be mastered (totaling over 700 upon completion of six years of medical studies).

The new curriculum was a significant departure from traditional Latin American medical training, which relied fundamentally on lectures and other passive forms of education, and emphasized theoretical knowledge over acquisition of practical abilities and competencies. Even in the early 1990s, for example, a study of 60 medical schools in the region by the Pan American Health Organization (PAHO) and the Latin American Association of Medical Schools (ALAFEM) revealed that $70 \%$ of schools had no participation in their country's health services and only $17 \%$ used primary care as an academic setting. What's more, students were not being trained to work in multidisciplinary teams with other health professionals, as was the case in the Cuban program.[3]

In practice, the new model represented an advance in terms of better integrating clinical medicine and population health, as well as bringing students into earlier contact with the population in general and with specific patients. It also fulfilled the goal of training more physicians for primary care: in the 1990 s, nearly 38,000 physicians graduated, four times the yield from the 1970s; and by 2003 , 30,000 of Cuba's 68,000 physicians were practicing as family doctors, over 21,000 of them as specialists in family medicine.[4] This rapid extension of the family doctor program across the country brought with it another shift, increasing students' time in primary care settings from $10 \%$ of classes and rotations to approximately $20 \%$ by the turn of the century.

Yet, the program still had various shortcomings: students were being asked to adopt a more generalist approach to medicine, but they were being trained by specialists (in both basic and clinical sciences) who did not necessarily share this perspective and therefore could not serve as role models; clinical training was hospital-based, with periodic incursions into primary care; and basic sciences, clearly separated from the cycle of clinical years, were taught in medical school lecture halls. The result was a Flexnerian curriculum with some innovations. A dialogue conducted across Cuba with some 17,000 health professionals - mainly doctors — in 2003-2004 revealed related perceptions of difficulties still facing the profession, such as a persisting underestimation of primary care physicians' capabilities among physicians practicing at secondary and tertiary levels, and continued problems in selection of medical students.[5]

Even so, this curriculum accomplished what no other had in Cuba's history by closely matching the professional profile of the graduate with the needs of the health system and the population. Viewed within an international context, its implementation fit the criteria outlined by Charles Boelen during his tenure at the World Health Organization (WHO) for developing what he and the World Organization of Family Doctors (WONCA) referred to as the "five-star doctor." This was a doctor, they said, who should possess "a mix of aptitudes to carry out the range of services that health settings must deliver to meet the requirements of relevance, quality, costeffectiveness and equity in health."[6] The Cuban family physician profile meshed well with the attributes used to describe the fivestar doctor:

- Care-giver (physical, mental and social): including comprehensive continuous curative, preventive, and rehabilitative care.

- Decision-maker: choosing the best way to address health problems, often within resource constraints, equitably benefiting patients and communities.

- Communicator: persuading individuals, families and communities to adopt healthy lifestyles and become partners in the health effort.

- Manager: assimilating and sharing knowledge within multidisciplinary teams, working in partnerships for social development.

- Community leader: understanding the determinants of health in the physical and social environment, taking positive interest in community health activities benefiting large numbers of people.[6]

\section{Scaling Up for Cuba and the Developing World}

The latest curricular reform in Cuba was initiated in 2004-2005 with the sweeping transfer of academic training from medical school campuses to community polyclinics. This new model makes room for significant expansion of enrollment in response to the country's commitment to train more Cuban doctors for service at home and abroad, as well as thousands of new physicians from developing countries.

Providing medical education to foreign students was not new for Cuba: from the early 1960s through 2004, 3,612 students from the world over had received MDs in Cuba. This commitment was substantially strengthened by the opening of the Latin American Medical School (ELAM) in 1999, reflecting a decision by the $\mathrm{Cu}-$ ban government to adopt training of human resources in health as its main long-term contribution to addressing the global health crisis. The government initially offered to train 10,000 physicians at ELAM, providing full scholarships to students who generally came from low-income families in Latin America and the Caribbean. This initiative complemented Cuban participation in expanding medical education in Africa. At the school's first graduation in 2005, President Fidel Castro elevated Cuba's international commitment once more, pledging to graduate 100,000 doctors from the Global South by 2015.[7] Medical school enrollment of Cubans has increased since 2000 to keep pace with growing demand for Cuban doctors in other countries, who volunteer through a program providing medical services in poor and marginalized communities since 1963. 


\section{Policy \& Practice}

However, training was still limited to relatively "small-scale scaling up." It was the Barrio Adentro program in Venezuela that provided an impetus for the most innovative curricular reform to date, encompassing a new proposal for increasing medical training in developing countries worldwide. Barrio Adentro was established by the Venezuelan government in 2003-2004 to extend primary health care to the entire country through community-based clinics staffed primarily by Cuban doctors $(14,000$ by 2008 , of a total of over 70,000 Cuban physicians practicing at home and abroad). Venezuelan health authorities concluded that, in order to fully staff a comprehensive, national public health system; replace the Cuban doctors; and assure full coverage for all sectors of the population, they needed to train another 20,000-30,000 physicians as soon as possible. In Cuba, meanwhile, an abrupt increase in the numbers of family doctors serving abroad - the largest group in Venezuela - prompted the reorganization of primary health care services to satisfy public demands, adding to the need for stepped-up training of more Cuban doctors at home. [8] Finally, a key factor facilitating development of a new model was resources: in the case of Venezuela, financial resources for major investments in health and medical education infrastructure; and in Cuba's case, primarily human resources - medical educators with decades of experience in curriculum design.

As a result, new and quite similar medical education programs have developed in the two countries simultaneously: Venezuela's "medical university without walls" (see National Training Program for Comprehensive Community Physicians, Venezuela in this issue) is mirrored by the University Polyclinic Medical Training Program (UPMTP) in Cuba, which now involves 292 of the country's 498 polyclinics. In this model, $75-80 \%$ of all training takes place in community primary care facilities, with an accredited polyclinic (including its clinical and expanded laboratory and rehabilitation facilities; documentation center; and computer-equipped classrooms) as the central teaching unit, where theoretical content is reinforced by practical activity. One-quarter of students' six-year training takes place in hospitals and other facilities.

In both the Cuban and Venezuelan programs, professors are practicing primary care physicians, "physician-tutors," who receive additional post-graduate training to assimilate their teaching role and the subject matter for each course. CD- and video-based lectures

University Polyclinic Medical Training Program (UPMTP), Cuba, 2008-2009 Academic Year*

\begin{tabular}{|c|c|c|c|}
\hline \multicolumn{4}{|l|}{ YEAR ONE } \\
\hline & \multicolumn{3}{|c|}{ Comprehensive General Medicine (Family Medicine) I (20 weeks) } \\
\hline Semester 2 & $\begin{array}{l}\text { Morphophysiology III: Nervous System } \\
\text { (11 weeks) }\end{array}$ & $\begin{array}{l}\text { Morphophysiology IV: Metabolism, } \\
\text { Endocrine and Reproductive Systems } \\
(10 \text { weeks) }\end{array}$ & \\
\hline \multicolumn{4}{|c|}{ YEAR TWO } \\
\hline Semester 1 & $\begin{array}{l}\text { Morphophysiology IV (continued), History (6 } \\
\text { weeks each); Family Medicine III, English III, } \\
\text { Physical Education III ( } 16 \text { weeks each) }\end{array}$ & $\begin{array}{l}\text { Morphophysiology V, History of Cuba } \\
\text { (10 weeks each) }\end{array}$ & Morphophysiopathology I (1 week) \\
\hline \multirow[t]{2}{*}{ Semester 2} & Morphophysiopathology I (continued, 9 weeks) & Morphophysiopathology II (12 weeks) & \\
\hline & \multicolumn{2}{|c|}{$\begin{array}{l}\text { Family Medicine IV, Psychology of Health Care I, Health Information Technology II, } \\
\text { English IV, Physical Education IV ( } 21 \text { weeks each) }\end{array}$} & \\
\hline Semester 2 & \multicolumn{2}{|c|}{ Internal Medicine, Pharmacology II, English VI (20 weeks each) } & \\
\hline \multicolumn{4}{|c|}{ YEAR FOUR } \\
\hline \multirow[t]{2}{*}{ Semester 1} & Family Medicine V (6 weeks) & General Surgery (10 weeks) & Obstetrics \& Gynecology (10 weeks) \\
\hline & \multicolumn{3}{|l|}{ English VII (24 weeks) } \\
\hline Semester 2 & Pediatrics (16 weeks) & English VIII (13 weeks) & \\
\hline \multicolumn{4}{|l|}{ YEAR FIVE } \\
\hline \multirow[t]{2}{*}{ Semester 1} & Public Health (9 weeks) & Family Medicine VI (7 weeks) & Psychiatry (6 weeks) \\
\hline & English IX (10 weeks) & & \\
\hline Semester 2 & $\begin{array}{l}\text { Traumatology \& Orthopedics } \\
\text { (6 weeks) }\end{array}$ & $\begin{array}{l}\text { Urology, Otolaryngology, Ophthalmology, } \\
\text { Dermatology, Tropical Medicine } \\
\text { (3 weeks each) }\end{array}$ & English $\mathrm{X}$ (11 weeks) \\
\hline
\end{tabular}

*Does not include elective or examination periods. Internship is followed by state licensing examination.

Source: Ministry of Public Health, Havana. Vice Ministry for Medical Education and Reseach. September 1, 2008. 
by prominent professors in each discipline are used as core material, supported by problem-based and other active learning methods guided by physician-tutors, and a bibliography that students are expected to consult on their own.

The UPMTP model exists side-by-side with the "traditional" Cuban curriculum, in which the main academic settings are medical school classrooms and hospitals, with students rotating through polyclinics and other primary care settings rather than being based there. For the 2006-2007 academic year, 16,975 students were enrolled in the traditional curriculum; and 12,122 in the UPMTP communitybased curriculum, a total of more than 29,000 Cuban students.[9]

Since 2007, both Cuban models and the one developed for Venezuela have made innovations in teaching methods by introducing the discipline of morphophysiology, which integrates various biomedical sciences, including anatomy, normal histology, embryology, normal and pathologic physiology, and cellular and molecular biology, among others. Morphophysiopathology has also been developed as a discipline, covering basic sciences related to clinical practice, such as clinical laboratory, imaging, parasitology, microbiology, and anatomic pathology. In the traditional model, these are taught at the medical schools; in the UPMTP curriculum, they are taught at the polyclinic (Figure 1).

Cuban medical educators continue to review and fine-tune the University Polyclinic curricular design, with special attention to elements that might be adapted for Cuba from the Venezuela program. The sixth year in all three programs - the traditional Cuban model, the University Polyclinic, and community-based training in Venezuela - is an internship period at the primary care level.

\section{Each One Teach One}

Teaching has been included among the competencies and attributes of the Cuban family physician since the curriculum reform of the 1980s. Since then, interns and residents have participated in student education; and Cuban doctors abroad also regularly teach health promoters, midwives and others at the community level. But it was not until the advent of the Barrio Adentro and University Polyclinic models that the door opened to scaling up medical training for unprecedented numbers of doctors in other developing countries - without the need for major infrastructure and related investments - simply by recruiting qualified students from communities-in-need, offering postgraduate pedagogical training to the Cuban physicians already working in those communities, and outfitting community classrooms with computers, other audio-visual equipment and a modest printed bibliography.

Thus, the new Cuban models propose not a five- but rather a sixstar doctor, adding another vital function to those of care-giver, communicator, manager, decision-maker and community leader. To contribute to resolving the global shortfall of trained health professionals, making "health for all" possible, the qualified twenty-first century-doctor must also be a teacher.

\section{Challenges Ahead}

Cuba's new curricular models face three major challenges. The first is quality assurance - guaranteeing quality of the teachinglearning process without relinquishing the large numbers of students enrolled, who are the future physicians urgently needed by their communities. This is particularly challenging in the early phases of implementation when the educational design is new to every participating person and institution. In both the Venezuelan and University Polyclinic curricula, several quality assurance mechanisms have been put in place: in addition to preparatory courses, physician-tutors must be accredited to teach and must continue to scale the ladder of academic rank throughout their professional careers. In Cuba, each polyclinic must also be accredited by the provincial medical school, and MINSAP periodically carries out external evaluations to assess performance of the medical schools themselves and of all institutions authorized as teaching facilities.

While final proof of success or failure can only be measured in medium- and long-term health outcomes, several longitudinal studies are currently under way in Cuba to evaluate aspects of the University Polyclinic program, including knowledge and skills acquired by students; student-faculty-patient satisfaction; polyclinic organization; effectiveness of academic training; and impact of medical education in health care delivery. These studies are directed by the Higher Institute of Medical Sciences of Havana and other medical schools, as well as the National School of Public Health, and will compare results with the traditional curricular model.

The second challenge is adapting the new models to countries with fewer resources, and the third challenge is overcoming opposition to physician training on such a large scale. Lingering incomprehension in Cuba is perhaps the most easily addressed concern, since it comes from a minority of health professionals who are resistant to such radical transformations. But in some countries, tradition may be more firmly ingrained, with professionals less open to considering new options, even in the face of dire shortages or maldistribution of the physician workforce. And in those countries where private practice is the rule, entrenched interests within the medical profession itself can present formidable obstacles to adoption of any model that would economically affect their client base. In such cases, tipping the balance will depend on the political will of governments and their leaders, and upon the demands for health care voiced by the underserved themselves.

\section{References}

1. Delgado García G. El servicio médico rural en Cuba. Antecedentes y desarrollo histórico. Cuadernos de Historia de la Salud Pública No. 72: Temas y personalidades de la historia médica cubana. Havana: Consejo Nacional de Sociedades Científicas; 1987.

2. Government of Cuba. Ministry of Public Health. Folleto del Servicio Médico Rural [undated mimeographed report].

3. Fernández Sacasas J. Educación médica superior: realidades y perspectivas a las puertas del nuevo siglo. Havana: Centro Nacional de Perfeccionamiento Médico; 1999.

4. Government of Cuba. Ministry of Public Health. National Statistics Division. Anuario Estadístico de Salud 2005. Havana; 2006.

5. Fernández Sacasas J. El diálogo ético en la ofensiva por la excelencia. Rev Cubana Salud Pública. [serial on the Internet] 2006;32(4). [cited 12 Sep 2008] Available from: http://scielo.sld.cu/scielo.php?script=sci_arttext\&pid=S086434662006000400005\&lng=es\&nrm=iso\&tlng=es

6. Boelen C. The five-star doctor: An asset to health care reform? [monograph on the Internet]. Geneva: World Health Organization; 1993. [cited 23 Aug 2008]. Available from: https://www.who.int/hrh/en/HRDJ_1_1_02.pdf

7. Castro Ruz F. Speech at the first graduation of students from the Latin American Medical School. Havana. 20 Aug 2005. [monograph on the Internet]. [cited 5 Sep 08]. Available from: http://www.cuba.cu/gobierno/discursos/2005/ing/ f200805i.html.

8. Edith D, Terrero A Salud pública cubana: Otra vuelta de rosca. Bohemia [serial on the Internet]. 24 Mar 2008. [cited 23 Aug 2008]. Available from: http:// bohemia.cu/2008/03/24/encuba/salud.html.

9. Government of Cuba. Ministry of Public Health, Vice Ministry for Medical Education and Research. Matrícula definitiva por carreras curso 2007-2008. [database] 2008 Jan 28. 